\title{
Traffic Noise Study on Muzaffarnagar Byepass
}

\author{
S. Praveen ${ }^{1}$ and Dr. S.S. Jain ${ }^{2}$ \\ ${ }^{1}$ CVR College of Engineering, Civil Engineering Department, Ibrahimpatan, R.R.District, A.P, India \\ Email: samarthipraveen@gmail.com \\ ${ }^{2}$ Professor, Indian Institute of Technology Roorkee, Civil Engineering Department, Roorkee, Uttarakhand, India \\ Email:ssjanfce@iitr.er.net
}

\begin{abstract}
Noise Pollution has become a major concern to planners, regulatory agencies affecting individuals and communities. Most of the countries, keeping in view the alarming increase in environmental noise pollution has set permissible noise standards. Road surface, speed of the traffic, gradient of the road, traffic flow etc. are the different factors affecting noise level on a highway. The Bureau of Indian Standards (BIS) has recommended an acceptable noise level of 25-35 dB (A) for non-Urban areas. A number of noise predicting models have been developed over the past 30 years that attempted to model the highway conditions under study. Useful correlations has been found to exist between traffic parameters like traffic volume, average speed of traffic stream and noise parameters like Equivalent sound energy level (Leq) in the locations. With the help of these correlations, it is possible to predict the impact of traffic developments in terms of noise pollution in future.
\end{abstract}

Index Terms - Noise pollution, Traffic Speed, Traffic flow and Models

\section{INTRODUCTION}

Noise is defined as unwanted sound. Sound is produced by the vibration of sound pressure waves in the air. Sound pressure levels are used to measure the intensity of sound and are described in terms of decibels. The decibel $(\mathrm{dB})$ is a logarithmic unit which expresses the ratio of the sound pressure level being measured to a standard reference level. Sound is composed of various frequencies, but the human ear does not respond to all frequencies.

Frequencies to which the human ear does not respond must be filtered out when measuring highway noise levels. Sound-level meters are usually equipped with weighting circuits which filter out selected frequencies.

It has been found that the A-scale on a sound-level meter best approximates the frequency response of the human ear. Sound pressure levels measured on the Ascale of a sound meter are abbreviated $\mathrm{dB}$ (A). Noise is unacceptable and causes trouble to human beings. Noise pollution has become a major concern of communities living in the vicinity of major highway corridors. The exposure of noise from highways affects more people than noise from any other source. Several federal and State agencies have implemented regulations that specify procedures to conduct noise studies. These regulations have led to the advancement of computerized method for predicting highway noise. In general noise has three sources i. Operational noise from transportation system

ii. Occupational or Industrial Noise

iii. Community Background Noise.

Among these operational noises from transportation system alone contribute about $70 \%$ of total noise whereas road traffic noise is responsible for $55 \%$ of total noise.

Sound intensity decreases in proportion with the square of the distance from the source. Generally, sound levels for a point source will decrease by $6 \mathrm{~dB}$ (A) for each doubling of distance. Sound levels for a highway line source vary differently with distance, because sound pressure waves are propagated all along the line and overlap at the point of measurement. A long closely spaced continuous line of vehicles along a roadway becomes a line source and produces a $3 \mathrm{~dB}$ (A) decrease in sound level for each doubling of distance. However, experimental evidence has shown that where sound from a highway propagates close to "soft" ground (e.g., plowed farmland, grass, crops, etc.), the most suitable drop off rate to use is not $3 \mathrm{~dB}(\mathrm{~A})$ but rather $4.5 \mathrm{~dB}(\mathrm{~A})$ per distance doubling. This $4.5 \mathrm{~dB}$ (A) drop off rate is usually used in traffic noise analyses.

For the purpose of highway traffic noise analyses, motor vehicles fall into one of three categories:

i. Automobiles -vehicles with two axles and four wheels,

ii. Medium trucks - vehicles with two axles and six wheels, and

iii. Heavy trucks - vehicles with three or more axles

The emission levels of all three vehicle types increase as a function of the logarithm of their speed.

The level of highway traffic noise depends on three things:

a. The volume of the traffic,

b. The speed of the traffic, and

c. The number of trucks in the flow of the traffic.

Generally, the loudness of traffic noise is increased by heavier traffic volumes, higher speeds, and greater numbers of trucks. Vehicle noise is a combination of the noises produced by the engine, exhaust, and tyres. The simulation techniques for unrestricted traffic in urban situations and Sabir (1988) conducted noise level survey for community noise $\&$ peak noise emission. The survey was conducted at six sites in the eastern province of Saudi Arabia and two sites in New Delhi, India.

\section{METHODOLOGY}

To determine noise studies some of the organization like CPCB (situated in New Delhi), CRRI, Delhi traffic 
police, Delhi administration and Centre of transportation Engineering (COTE), Roorkee have conducted a number of traffic flow noise pollution studies at selected mid block and important highway intersection in Delhi. Most of the studies were confined to only evaluating the noise pollution.

Kumar, Mehndiratta and Sikdar in 1993 studied the variation in noise pollution for buses running in different gears. The noise pollution data were recorded inside the running bus and trucks near the driver seat (near engine), in the middle of the bus and on the back seat of bus. Various correlations between the engine gear vehicle speed and noise parameter have been developed.

Gupta, Khanna and Gangil (1979) attempted to develop relationship between the vehicular noise and strem flow parameters. The Uttarakhand state highway No.45 passing through Roorkee was selected as the study area between Polaris intersection to Roorkee Talkies inter-section. The developed prediction equation for the noise level $\mathrm{L}_{10}$ is given below.

$\mathrm{L}_{10}=18.092433+19.90357 * \log _{10}\left(\mathrm{Q}_{\mathrm{w})} \quad \mathrm{dB}(\mathrm{A})\right.$

Where $\mathrm{Q}_{\mathrm{W}}=$ Traffic volume in EPCU/hr.

In the present study, 117th $\mathrm{km}$ on NH58, Muzaffarnagar Byepass Road was selected for field studies. The data collection was carried out in two locations L1 and L2 respectively.L1 indicates Delhi to Roorkee road and L2 indicates Roorkee to Delhi road at Muzaffarnagar Byepass.

At the site the following data have been collected:

1. Traffic Noise Levels

2. Classified Traffic Volume

3. Speed

Individual vehicle noise levels were taken and classified in to different categories.

1. Car, Jeep, Van

2. Scooter, Motor cycle (2-Wheeler)

3. Bus,

4. Truck

5. 3-Wheelers

\section{STUDY AREA}

The traffic study area considered was $117^{\text {th }} \mathrm{km}$ Road, NH58, Muzaffarnagar Byepass Road in Uttarkhand state. Data has been collected for traffic noise levels for different category of vehicles, spot speed and traffic volume simultaneously. The locations that were considered are Delhi-Roorkee Road (L1) and RoorkeeDelhi Road (L2). Traffic sample data was collected for one hour duration at three points which are away from the pavement edge (namely S1, S2, S3).Details of different measurements carried were given below.

\section{A. Noise level}

To record the traffic noise levels, noise level meter no. NL 2100B was used. It was placed at a specified distance from the pavement edge and at a height of $1.2 \mathrm{~m}$ from the ground level. Its microphone was placed right angle to the direction of traffic flow.

A noise sample size of 15 minute in each hour at a particular selected distance from the edge pavement was taken. Noise samples were collected in $\mathrm{dB}(\mathrm{A})$ scale at every 15 second interval (i.e. 4 counts per minute) or total 40 reading in one sample size.

For every noise sample, cumulative frequency data has been calculated. Similarly for both locations computations are shown in figure 1 and figure 2.

\section{B. Traffic Volume}

In India most commonly used method for traffic volume is the manual method for a shorter duration (up to $24 \mathrm{hrs}$ ) volume counts. The details such as vehicle classification and number of occupants can easily be obtained in manual method. Sometimes, when traffic volume is very high and manually it is not possible to record it more accurately time-lapse photographic technique (TLP) or VRT is employed.

In the present studies, it has been done through manual counts.

At the two selected study locations (L1 \& L2) one hour classified traffic volume data were recorded, in a predesigned, hourly traffic volume recording proforma which are subdivided in 5 minute time interval columns.

For this purpose, four semi skilled persons were employed i.e. two in each direction.

\section{Spot speed measurements}

A Doppler speedometer was used for measuring the spot speeds in KMPH. Speed for all the categories of the vehicles were recorded in a predesigned proforma for hourly duration, which is sub-divided in to 5 minute interval columns.

To facilitate the computations, the first step in the analysis of the observed speed data of whole traffic stream was grouped into speed-class intervals and a frequency distribution table was prepared for every hourly observed spot speed data, at all study locations.

For each Location frequency distribution table has been prepared similar to location 1(Roorkee to Delhi) and Location 2 (Delhi to Roorkee).

IV. OBSERVATIONS, RESULTS AND DISCUSSIONS

\section{A. General}

The observations, analysis and discussions upon computations of noise, volume and Speed Data are presented. The traffic parameters such as Passenger Car Noise Equivalence (PCNE) have been calculated from the computations.

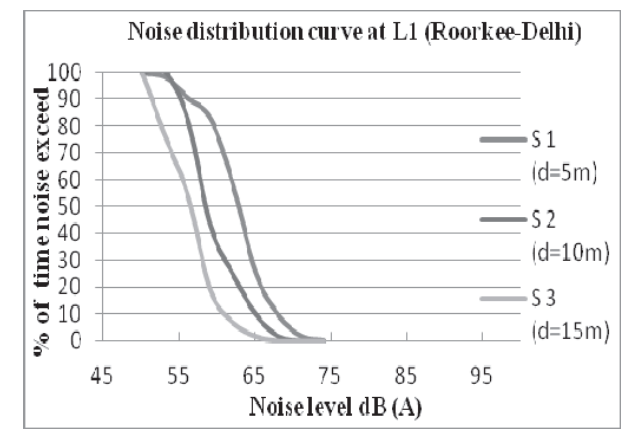

Figure 1 Noise Level Distribution Curve at L1 Location: $117^{\text {th }} \mathrm{km}$ Road, NH58, Muzaffarnagar Bye pass, 


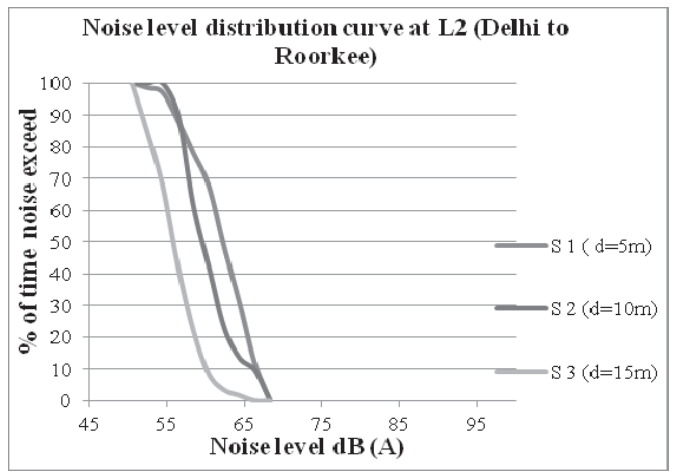

Figure 2 Noise Level Distribution Curve at L2

Location: $117^{\text {th }} \mathrm{km}$ Road, NH58, Muzaffarnagar Bye pass,

Note: S1,S2 and S3 are the samples, distance away from the pavement at $5 \mathrm{~m}, 10 \mathrm{~m}$ and $15 \mathrm{~m}$ respectively.L1 is location of Roorkee-Delhi route. L2 is location of DelhiRoorkee route.

\section{Interpretation of Results and Discussions:}

The work consists of an exclusive study of traffic noise on a two way, two lane rural highway of Muzaffarnagar Byepass road. As observed from the analysis, the noise observed on 3 sample points that were taken on both locations show high noise levels than the permissible limit of rural highways. As according to BIS the acceptable noise level of 25-35 $\mathrm{db}(\mathrm{A})$ for non-Urban areas.

\section{B. Determination of Speed Distribution Curve}

Speed distribution curve has drawn for each sample and their fifty percentile speed has been calculated and presented.

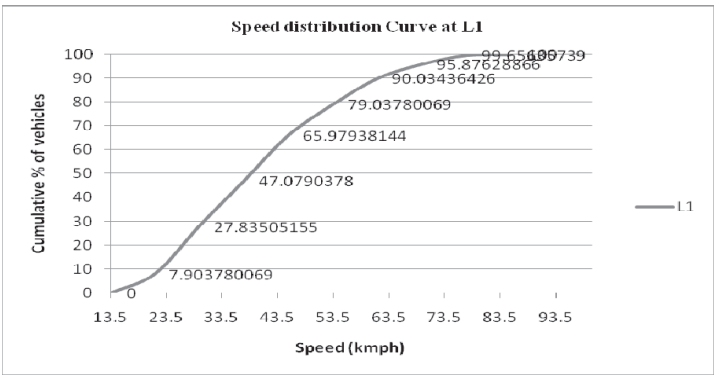

Figure 3 Cumulative Speed Distribution Curve at L1 (Delhi-Roorkee Road)

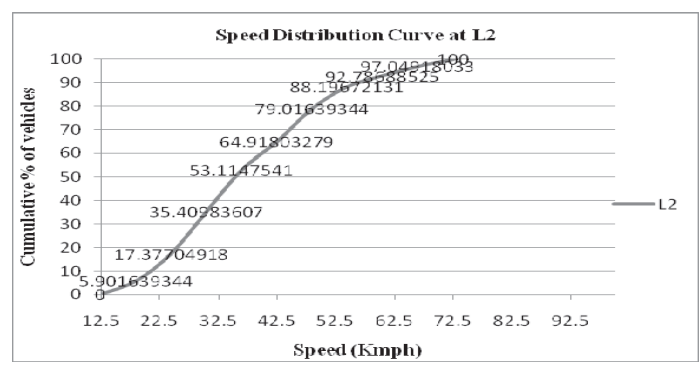

Figure 4 Cumulative Speed Distribution Curve at L2 (Roorkee-Delhi Road)

\section{Determination of Passenger car noise equivalence} (PCNE)
It is defined as that no. of free flowing passenger cars under standard traffic flowing passenger cars under standard traffic flow conditions which generate noise level equal to that of particular category of vehicle. The PCNE for any particular type of vehicle whose noise levels is $\mathrm{L}_{\mathrm{T}} \mathrm{dB}(\mathrm{A})$ is given by

$$
\mathrm{n}=10_{\mathrm{T}}^{(\mathrm{L}-\mathrm{L}) / 10}
$$

Where $\mathrm{L}_{T}$ is noise level of the vehicle, $\mathrm{L}_{\mathrm{C}}$ is noise level of car.

The Cumulative Noise Distribution for Different category of Vehicles for PCNEs are calculated.

TABLE 2

Determination of 50 Percentile Noise levels

\begin{tabular}{|c|c|c|c|c|c|}
\hline $\begin{array}{c}\text { Category of } \\
\text { Vehicles }\end{array}$ & Bus & Truck & Car & $\begin{array}{c}2- \\
\text { wheelers }\end{array}$ & $\begin{array}{c}3- \\
\text { wheelers }\end{array}$ \\
\hline $\begin{array}{c}50 \\
\text { Percentile } \\
\text { Noise level } \\
\text { dB (A) }\left(\mathrm{L}_{\mathrm{T}}\right)\end{array}$ & 87.5 & 82 & 79 & 80 & 68 \\
\hline
\end{tabular}

\section{PCNE of Bus}

$$
\begin{aligned}
\mathrm{n} & =10^{(\mathrm{L}-\mathrm{L}) / 10} \\
& =10^{(87.5-79) / 10}=7.08
\end{aligned}
$$

Similarly, PCNE of Traffic Stream are calculated as follows:

TABLE 3

Determination of PCNE for different category of vehicles.

\begin{tabular}{|c|c|c|c|c|}
\hline $\begin{array}{c}\text { Category of } \\
\text { Vehicles }\end{array}$ & Bus & Truck & 2-wheelers & 3-wheelers \\
\hline PCNE & 7.08 & 2.00 & 1.26 & 0.08 \\
\hline
\end{tabular}

TABLE 4

Determination of Noise levels

\begin{tabular}{|c|c|c|c|c|}
\hline $\begin{array}{c}\text { Location } \\
\text { Code }\end{array}$ & $\begin{array}{c}\text { Noise } \\
\text { Parameters } \\
\mathrm{dB}(\mathrm{A})\end{array}$ & $\begin{array}{c}\mathrm{S} 1 \\
(\mathrm{~d}= \\
5 \mathrm{~m})\end{array}$ & $\begin{array}{c}\mathrm{S} 2 \\
(\mathrm{~d} \\
=10 \mathrm{~m})\end{array}$ & $\begin{array}{c}\mathrm{S} 3 \\
(\mathrm{~d} \\
=15 \mathrm{~m})\end{array}$ \\
\hline L1 & Leq & 57.14 & 61.11 & 64.66 \\
(Delhi- & TNI & 54 & 64.5 & 70 \\
Roorkee) & LNP & 65.14 & 70.61 & 75.66 \\
\hline L2 & Leq & 59.44 & 61.61 & 66.86 \\
(Roorkee- & TNI & 59 & 65 & 74 \\
Delhi) & LNP & 68.44 & 71.11 & 78.36 \\
\hline Location & Percentile & $\mathrm{S} 1$ & $\mathrm{~S} 2$ & $\mathrm{~S} 3$ \\
Code & Levels & $(\mathrm{d}=$ & $(\mathrm{d}=$ & $(\mathrm{d}=$ \\
& & $5 \mathrm{~m})$ & $10 \mathrm{~m})$ & $15 \mathrm{~m})$ \\
\hline L1 & L10 & 60 & 66 & 67 \\
(Delhi- & L50 & 56 & 59.5 & 62.5 \\
Roorkee) & L90 & 52 & 56.5 & 56 \\
\hline L2 & L10 & 62 & 66.5 & 69.5 \\
(Roorkee- & L50 & 58 & 60 & 64.5 \\
Delhi) & L90 & 53 & 57 & 58 \\
\hline
\end{tabular}


TABLE 5

FHWA Noise Standards

\begin{tabular}{|c|c|c|}
\hline $\begin{array}{l}\text { Land } \\
\text { Use }\end{array}$ & $\begin{array}{l}\text { Design Noise } \\
\text { Level } \\
\mathrm{L}_{10}\end{array}$ & $\begin{array}{c}\text { Description of Land Use } \\
\text { Category }\end{array}$ \\
\hline $\mathrm{A}$ & $\begin{array}{c}60 \mathrm{~dB}(\mathrm{~A}) \\
\text { (exterior limit) }\end{array}$ & $\begin{array}{c}\text { For parks and open } \\
\text { spaces where quietness is } \\
\text { of primary importance }\end{array}$ \\
\hline B & $\begin{array}{c}70 \mathrm{~dB}(\mathrm{~A}) \\
\text { (exterior limit) }\end{array}$ & $\begin{array}{l}\text { Residential areas Hotels, } \\
\text { Schools, Churches, } \\
\text { Libraries, Hospitals etc. }\end{array}$ \\
\hline $\bar{C}$ & $75 \mathrm{~dB}(\mathrm{~A})$ & Developed areas \\
\hline $\mathrm{D}$ & $\begin{array}{c}55 \mathrm{~dB}(\mathrm{~A}) \\
\text { (interior limit) }\end{array}$ & $\begin{array}{c}\text { Residential areas, Hotels, } \\
\text { Libararies }\end{array}$ \\
\hline
\end{tabular}

\section{F. Relation Between Noise and Volume}

The correlation between volume and noise is found by plotting the values of Noise, Leq in $\mathrm{dB}(\mathrm{A})$ on $\mathrm{Y}$-axis and Volume in EPCNE/hr in X-axis respectively.

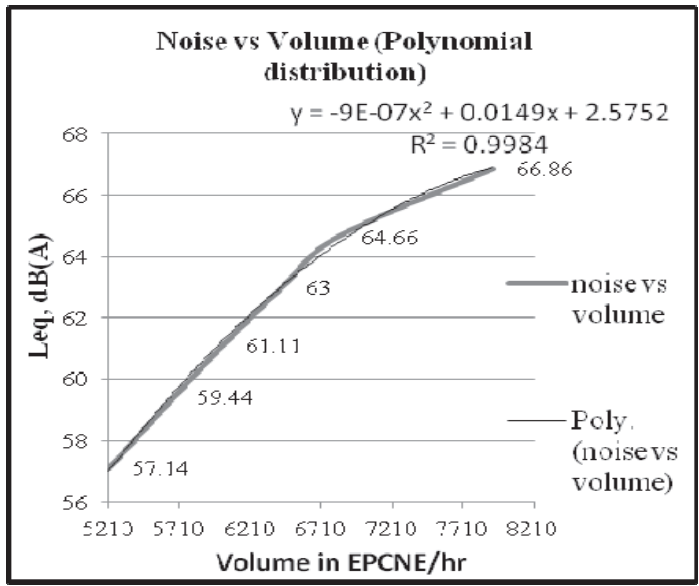

Figure 5 Noise vs Volume (Polynomial distribution)

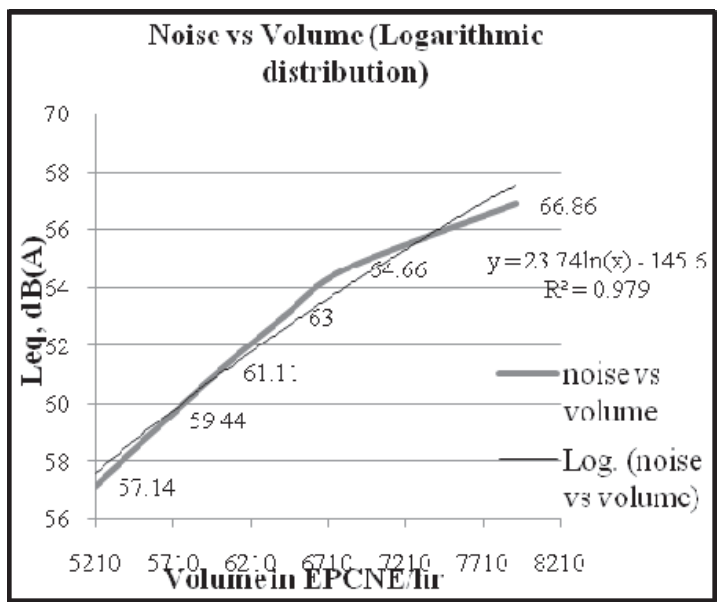

Figure 6 Noise vs Volume (Logarithmic distribution)

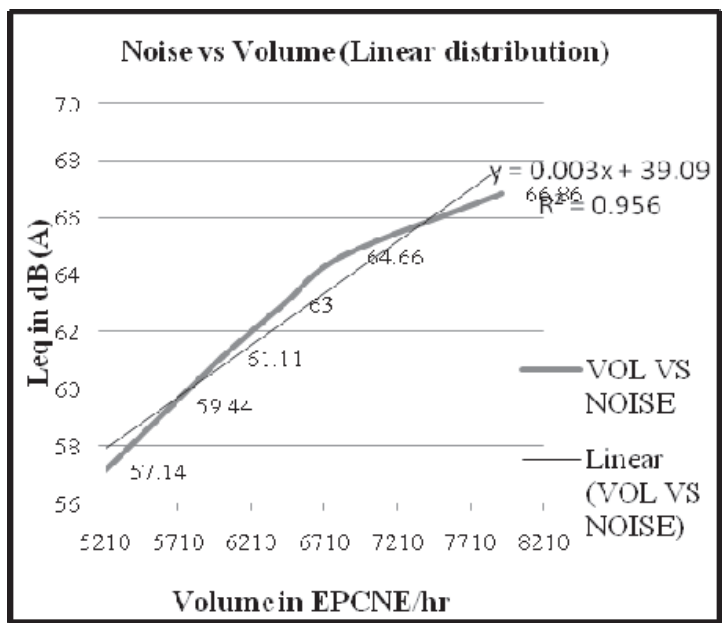

Figure 7 Noise vs Volume (Linear distribution)

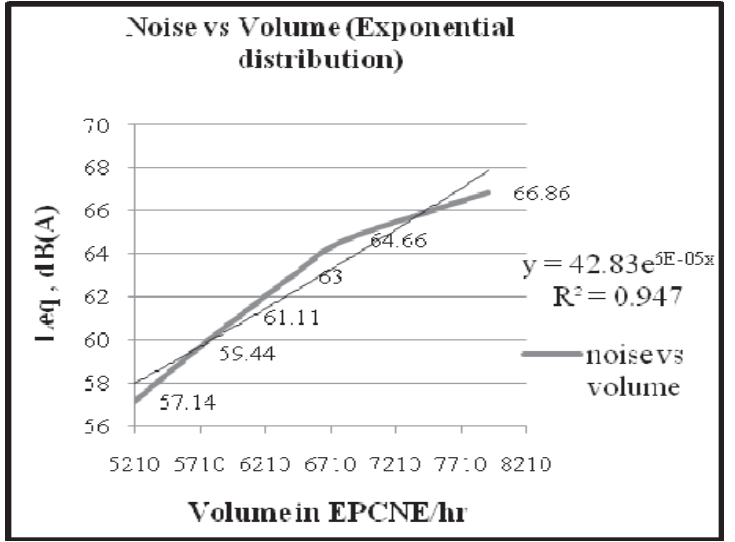

Figure 8 Correlation between Noise and Volume

Interpretation of Results and Discussions: A curve is plotted between noise and volume for a road having a capacity in terms of EPCNE/hr. Initially the curve shows the similar trend for the steady flow of traffic. But in case of congested flow it is expected that the noise level will show increasing trend up to certain value of volume and then it will again decrease at the very small value of volume. The reasons of expecting the above trend in case of congested flow were that the flow changes from steady to congested region the horning by the rear vehicles becomes more frequent either to get way to the vehicles or to overtake the frontal one. But none of the operations are possible in the congested flow and hence the chain of horning started as the vehicles arrive at the site. The decrease of noise level may be noticed, if the vehicle comes to the site at a big crowd, as the horning of vehicle stops. Therefore, in the total jam condition the noise level will be mainly because of the engines, and a chain of engine noise may lead to a higher noise level. As observed the Polynomial distribution gives the good correlation between Noise and Volume as its $\mathrm{R}^{2}=0.998$

\section{G. Relation Between Noise and Speed}

The correlation between Noise and Speed is found by plotting the values of Leq in $\mathrm{dB}(\mathrm{A})$ on Y-axis and Speed in $\mathrm{km} / \mathrm{hr}$ in $\mathrm{X}$-axis respectively in below Figures 


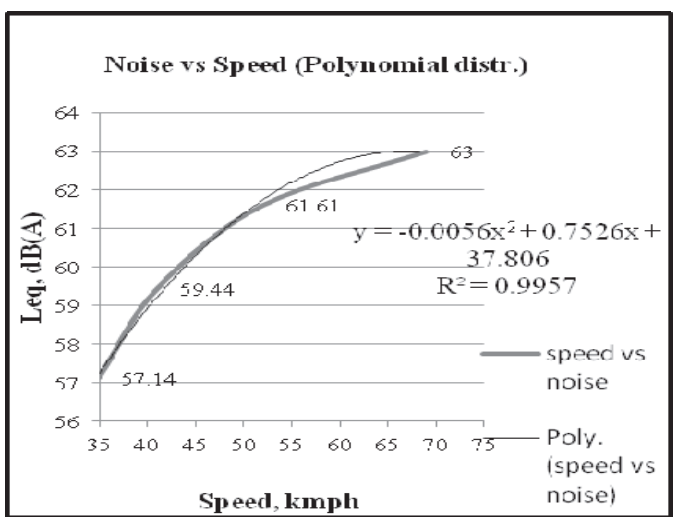

Figure 9 Noise vs Speed ( Polynomial Distribution)

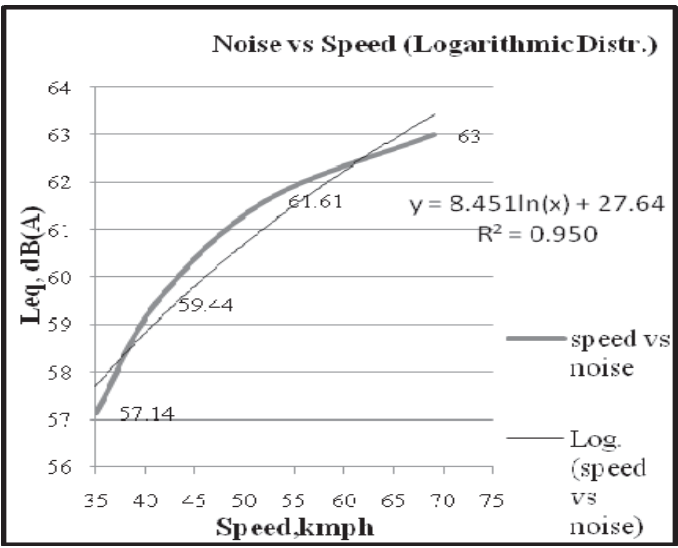

Figure 10 Noise vs Speed (Logarithmic Distribution)

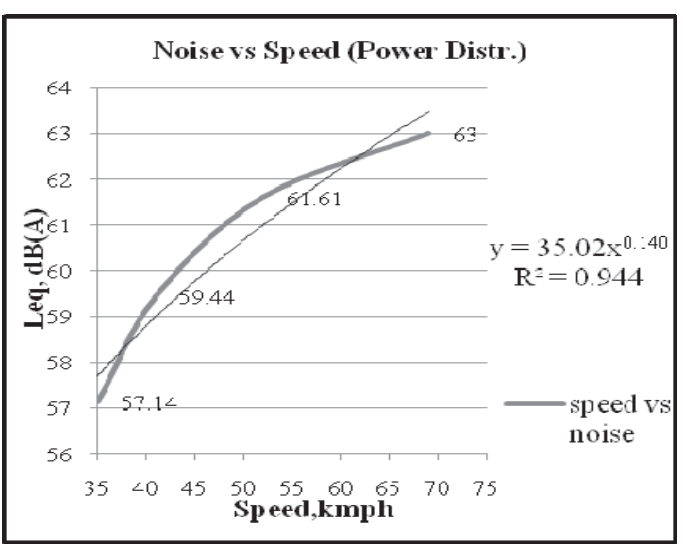

Figure 11 Noise vs Speed (Power Distribution)

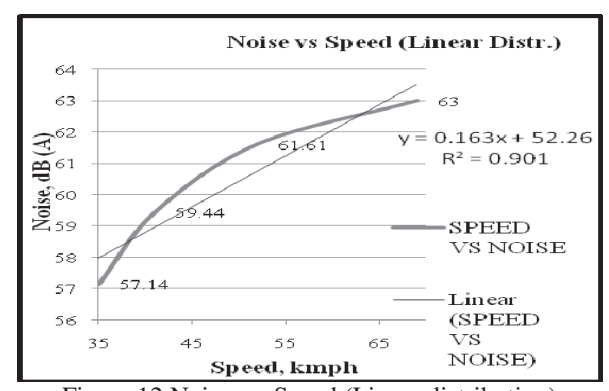

Figure 12 Noise vs. Speed (Linear distribution)

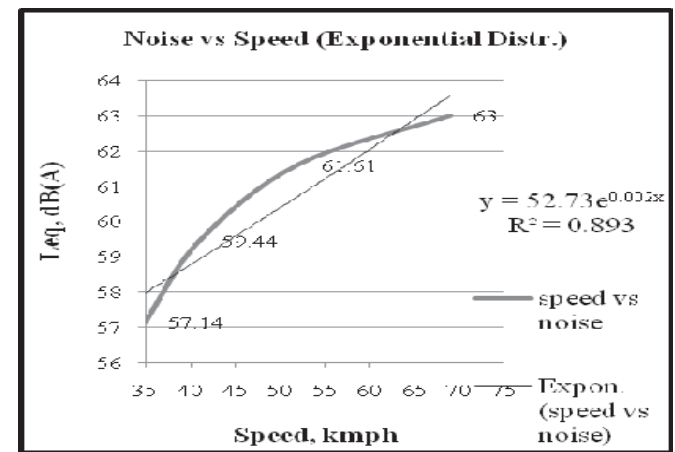

Figure 13 Noise vs Speed (Exponential Distribution)

Interpretation of results and discussions:Finally a curve is plotted between noise, Leq in $\mathrm{dB}(\mathrm{A})$ and Speed $(\mathrm{kmph})$ on $\mathrm{y}$-axis and $\mathrm{x}$-axis respectively. As observed from the curve it shows that at a particular speed, the noise of the vehicles increases as the speed of vehicle is increasing. This is due to as the vehicle reduces its speed the noise emission of vehicle and its horning also reduced, this mainly occurs at a congested traffic. As observed from the above figures, the Polynomial Distribution between noise and speed shows a good correlation as its $\mathrm{R}^{2}=0.9957$.

\section{CONCLUSIONS}

\section{A. Conclusions}

Following conclusions have been drawn based on the information presented in this report

1. The study has shown that the noise levels emitted by traffic noise in Location1 (RoorkeeDelhi) and Location2 (Delhi-Roorkee) were quite high.

2. The noise level decreases with the distance from the source of observation points.

3. Useful correlations have been found between traffic parameters like traffic volume, average speed and noise (Leq).

4. Traffic Volume affects the noise. As 200 vehicles passing in one hour sound half as loud as 2000 vehicles. So Volumes need to have a noticeable effect.

5. Reducing speed is the most immediate and equitable way of minimizing traffic noise.

6. A small increase in the percentage of heavy vehicles in the composition of flow may increase the noise level to a greater extent.

7. Major Traffic noise models throughout the world differ in some respects in detail but overall, the methodology is similar.

8. In order to overcome the problems the most effective one is to promote awareness on noise pollution and the risks of daily exposure to high noise levels. 


\section{B. Recommendations}

1. Detailed studies are to be carried out in 4-lane highways in order to study the noise of different categories of vehicles.

2. Studies for Traffic noise pollution reduction through eco-friendly noise barriers like trees etc. Should be conducted under varying conditions of land uses

\section{ACKNOWLEDGEMENT}

It is my great pleasure to express my sincere gratitude and immense veneration to my supervisor Dr. S.S. Jain, Professor, Transportation Engineering Group, Department of Civil Engineering, Indian Institute of Technology Roorkee, for his intuitive and meticulous guidance, valuable assistance in scrutinizing the manuscript and his valuable suggestions during the period of project work. I am also thankful to all my friends who directly or indirectly helped me during the period of completion of project.

\section{REFERENCES}

1. Alexander, A., Barde, J.Ph and Langdon.,(1975) "Road Traffic Noise", London Applied Science Publication, Vol.16, 34-38.

2. "FHWA MN Division Guidance for Evaluating Traffic Noise Impacts of local", federally funded projects that are exempt from State Noise Standards [31/1/2003]
3. IRC 104-1988, "Guidelines for Environmental Impact Assessment of Highway Projects", Jamnagar House , New Delhi.

4. "Highway Traffic Noise Analysis and Abatement Policy and Guidance" by U.S. Department of Transportation Federal Highway Administration Office of Environment and Planning Noise and Air Quality Branch, (1995). Washington, D.C.

5. Hothersall, David C., and Salter, Richard J.,(1979) "Transport and the Environment", Granada Publishing Limited, Crossby Lockwood staples, London.

6. Johnson, D.R., and Saunders, E.G., (1968) " The Evaluation of Noise from freely flowing Road Traffic", Journal of sound and vibration, Vol10, 287309.

7. Kumar, V.,(1979) "Analysis of Urban Traffic Noise", M.E. Dissertation, Civil Engineering Department, University of Roorkee, Roorkee, India,

8. Lloyd B. Arnold,.(2001) "Highway Noise Study Analysis", Environmental Engineer, Senior Environmental Division, Virginia Department of Transportation.

9. Pearson, D. Krik, and Sabir, S.M.,(1988) "Road Traffic in Developing Countries Assesssment and Prediction" Proceedings. ICORT, Centre of Transportation Engineering., Civil Engineering Department, University of Roorkee, Roorkee, India.

10. Rao, P.R., (1991) "Prediction of Road Traffic Noise", Indian Journal of Environmental Protection, Kalpana Corporation, Varanasi, Vol 11, 290-293.

11. Yap, X.W, Bavani, N., Ramdzani (1999) “An Effect of Traffic Noise on Sleep: A Case Study in Serdang Raya, Selangor",Faculty of Environmental Studies, University Putra Malaysi. 